\title{
Art and Interaction: Some Reflections
}

\author{
David England \\ Liverpool John Moores University \\ School of Computing and Maths \\ Liverpool L3 3AF, UK \\ d.england@ljmu.ac.uk
}

\begin{abstract}
This paper reflects on 20 years of collaborations with artists on art projects. We aim to explore the interplay between $\mathrm{HCl}$ theory and practice, and artistic theory and practice that has informed, supported and sometimes hindered the collaborations. The various collaborations have sprung from different sources and had different goals but interaction has been the linking theme.
\end{abstract}

Keywords: Art, interaction, fine art, new media art, $\mathrm{HCl}$ theory, art theory.

\section{INTRODUCTION}

Artists have been involved in interactive electronic media since Stockhausen (1967) with electronic music and Myron Krueger (1991) with camera vision. And as with other walks of life, interactive digital media has become part of the mainstream of artistic production and performance. More recently there have been some attempts to formalise the working relationship between art and technology. Thus there are a number of New Media Art institutes such as V2 in Rotterdam. There are also a number of new media art festivals such as Ars Electronica (www.aec.at) in Linz. Academically, Candy and Edmonds (2002) documented initial approaches to art-technology collaborations. The EPSRC LeonardoNet network (www.leonardonet.org) brought together technologists and arts and humanities researchers to develop a landscape document for interdisciplinary work.

This paper reflects on the author's collaborations with artists over 20 years. The work described below has involved both novel technology and novel collaborations, which have led to reflections on the value and nature of art-technology collaborations, and what they might mean for future collaborations. More specifically, we will examine what might be learnt for collaborations involving interactive technologies and what that might mean for the discipline of Human-Computer Interaction, and conversely what that might mean for artistic practice and theory.

Three projects are taken as case studies: Wet\&Sticky, Unmasking 3 and $\mathrm{HCl}$ Fun. We will firstly describe the three projects and reflect on the nature of their collaborations before ending with some overall lessons and proposals for supporting future collaborations.

\section{WET AND STICKY}

Wet and Sticky (1991) was envisioned by Tunde Cockshott as a means of overcoming some of the limitations of computer-based paint programs at that time. Cockshott likened those programs to potato stamps where, unlike real paint, the paint was static on the screen. Wet and Sticky used a cellular automaton approach to model the canvas as a array of cells full of paint. Algorithms would decide how the paint would move between the cells. Using a naïve model of physics, the "paint" would appear to flow and mix across the canvas. Paint added by brushes would interact with paint already on the canvas. Paint properties, such as dryness and viscosity, could be set by the user. Canvas properties such as absorption and gravity could also be set. Thus, having started with an imitation of paint, we also gave the artist a means with playing with the digital model, e.g. by having gravity acting in different directions in different parts of the canvas, opening up more possibilities for exploration and experimentation.

Though the program was successful in concept it raised a number of challenges in implementation and interaction. The speed of computation meant the paint flowed slowly across the screen so that thin, wet paints could not be fully realised. Experiments with an implementation on parallel computers, England, Cockshott (1991) raised questions of how to structure an interactive application on a platform designed for batch processing? Further than that, how do you design interaction for scenarios that involve parallel 
actions by both the user and system? These are still active research questions.

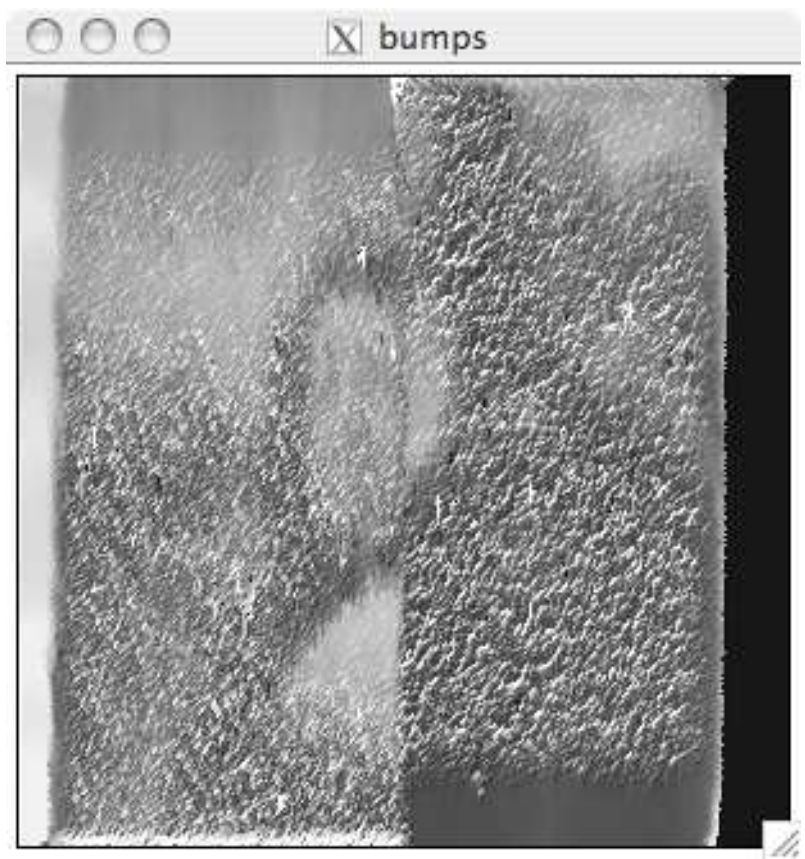

Figure 1. Gravity in 2 directions with textured paint

The collaboration process was an informal and accidental one where research goals happened to coincide to mutual enrich each other. However this is a key observation, aims and goals need not be similar between the partners but they do need to be mutually beneficial.

\section{UNMASKING 3}

Unmasking 3, Bamgboye et al (2001) was a formally commissioned artwork from FACT with the technical partners acting as subcontractors. The role of the artist was as conceptualiser while the technical partners were free to choose their implementation platform and tools, and the FACT curator acted as mediator between the artist and technical partner.

Ola Bamgboye is a Nigerian artist interested in the Diaspora of African art, which was taken by the colonial powers in the $17^{\text {th }}$ and $18^{\text {th }}$ Century. He focussed on $16^{\text {th }}$ Century bronze statue of a Queen Mother's head from what is now Benin, Nigeria. The statue is on display at the Liverpool World Museum. Similar bronzes can be found in European and North American museums. Ola's challenge, at the height of the doc-com boom was whether the head could be returned, digitally, to the descendants of its producers. The bronze was digitised by the museum staff producing a 3D model and then realised as a VRML model, Carey
\& Bell (1997) for display and manipulation on the web. The user was able to explore the colour, lighting and transform the $3 \mathrm{~d}$ model and share their results with others. However, given the relative immaturity of Web 3D technology the first concept demonstrator was not exhibited and a further version using Director, produced by Plymouth University was displayed at Spacex in Exeter, though lacking the sharing features of the original. Since that time VRML (and Web3D) have fallen out of favour as interactive technologies. Others are being explored, such as WebGL, but there is no agreed, usable, standard platform for interactive 3D web applications.

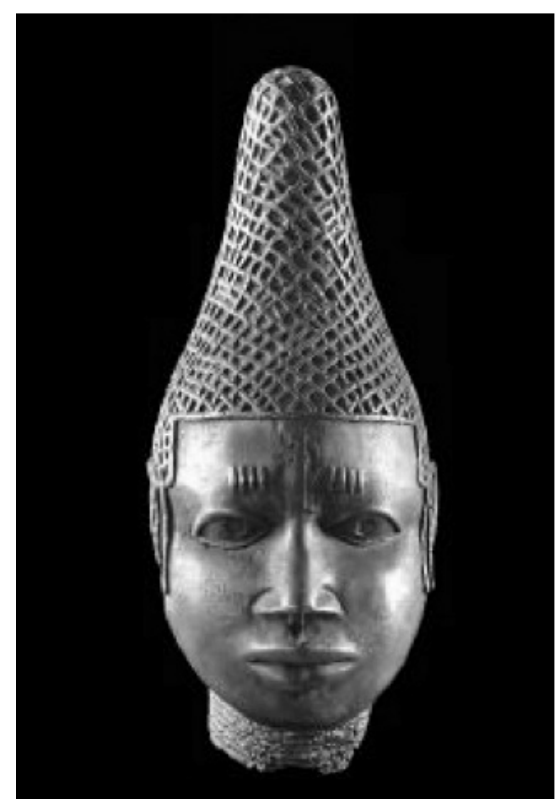

Figure 2 Queen Mother's Head Bronze

The artistic reception to the first demonstrator revealed further limitations of VRML where it was thought that the 3D model lost much of the aesthetics of the original bronze, which led to some discussion of the value of the real vs. the virtual representation.

\section{HCI FUN}

The $\mathrm{HCl}$ FUN project, England et al (2007) was conceived as an EPSRC Public Engagement with Science project. With our partners at FACT (www.fact.co.uk) the challenge was to produce some engaging interactive art works that would also express some concepts for $\mathrm{HCl}$. The project would be realised as an exhibition and a set of open workshops. A significant part of the project was searching for artists who would fit in with the project aims. Artists take as many different 
attitudes to technology as any other group. There are artists who reject technology and see it as interfering between their work and the audience. Other artists work to subvert and undermine technology to make their statements. And other artists play with the nature of technology to produce pieces with different degrees of engagement and accessibility.

We began working with artists Josh Nimoy, Caen Botto and Simon Poulter. Each of the artists took different approaches to the production of their work and their collaboration with us as project leaders, and with the exhibition curator, Marta Ruperez.

The art works that resulted were

- Mixed Hello - A interactive camera vision piece reflecting Myron Krueger by Josh Nimoy

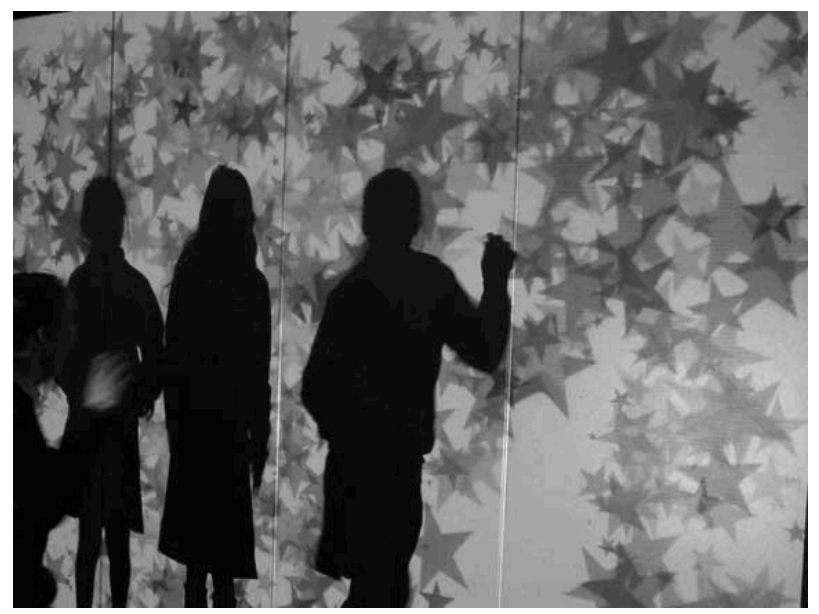

Figure 3 Mixed Hello

- C0D3 Mechanics of a Spell by Caen Botto - an installation and performance piece linking input devices to the production of sounds and visuals.

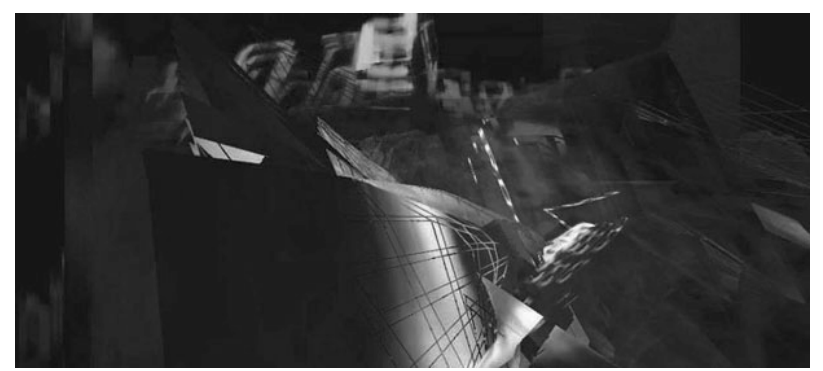

Figure 4 c0d3 visuals
- $\quad$ AKM - The Automated Knowledge Machine by Simon Poulter - An ATM that delivered knowledge

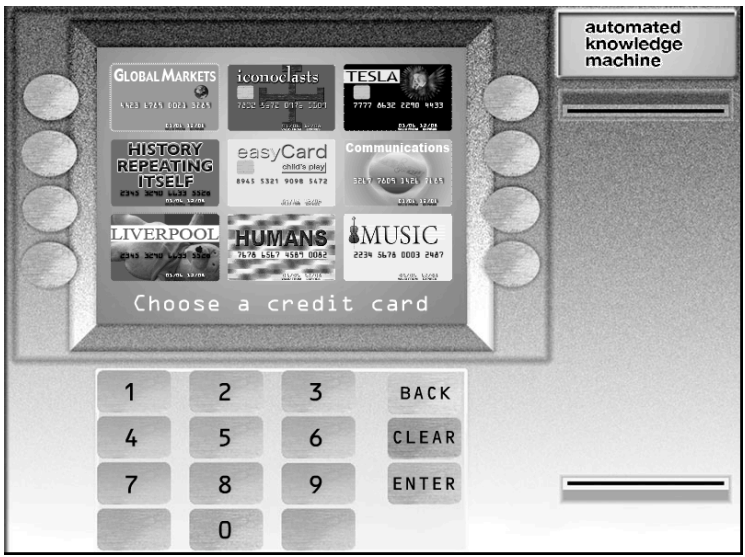

Figure 5 AKM

Further information can be found at the project website http://www.hci-fun.org.uk. The exhibition ran for two months with a series of additional weekend workshops. The main measure of evaluation was the public's attendance and engagement with the works and their reflections on the interaction.

The collaborations took different forms with each artist. With Nimoy there was a long-winded email exchange about the nature of icon and icon representation, which led initially to some desktop pieces that played around with these concepts. This led to the further development of Nimoy's camera vision piece, which again explored the nature of interaction and representation. The collaboration developed into an informal residency at FACT. With Botto the relationship was more conventional with the artist following the initial brief to produce a work based on MAXMSP and a range of non-traditional input devices. Both Nimoy and Botto acted as artist-programmers, developing their own technology. Poulter also worked in a more conventional artistic brief mode though used his own technical partner to help realise his artwork.

\section{SOME REFLECTIONS}

Over the period of these projects $\mathrm{HCl}$ has evolved through thinking influenced by, psychology (e.g. usability), sociology (e.g. ethnography) and philosophy (e.g. phenomenology). It could be argued that only recently, with more reflective approaches to $\mathrm{HCl}$, has it been able to investigate, evaluate and contribute more fully to the development of interactive art. Prior to this, the more scientifically motivated approaches to $\mathrm{HCl}$ have been at a loss to fully reason and argue about 
artistic endeavours in interaction. Much of art theory and practice, in new media, is exploratory and its outcomes maybe challenging. The interactive experiences produced therefore, maybe not meet standard usability criteria, or accord with accepted norms of collaboration. In fact, work such as c0d3 breaks the norms between user action and feedback. However, the artwork still produces an engaging and enjoyable experience. So there are questions about how we assess, evaluate and judge work with artistic aims compared with our everyday applications. Greenberg and Buxton (2008) have argued for a wider range of evaluation approaches in $\mathrm{HCl}$.

The same limitations apply to studying the practice of developing new media art works. They generally involve a great deal of prototyping and experimentation, which is motivated by honing the final user experience or artist performance. There may be some superficial similarities to prototyping in user interface design but whereas UI prototyping is driven by user needs and functionality, artistic prototyping is much more open-ended. Indeed the process of exploration is sometimes as important as the resulting artwork. Here we see an enhanced role for the new media Curator in documenting the artwork development process as part of the final exhibition or performance. As part of $\mathrm{HCl}$ Fun, Ruperez used the email logs as part of the exhibition documentation.

The curator's role brings us on to the different models of collaboration they we have experienced. We have moved from researchers, to equal participants, to subcontractors, to project managers. Each of these brings different demands and challenges. Apart from more informal collaborations, as in Wet\&Sticky, curators perform a valuable role in bringing collaborative projects together. Given their knowledge of exhibition design, meeting audience needs and understanding art history and theory, they can bring together the different partners and help to translate between the artistic and interaction aspects of a project. In most of the above projects there were separate but parallel and coinciding goals amongst the various participants. Indeed an important step in setting up art and interaction projects is reaching agreement of mutually beneficial goals. The participants also have to live with emerging and changing goals as a project progresses, even if this may conflict with the initial requirement of one or more of the project partners. Partners need to be open to contingent behaviour, which might provide value insights by the end of the project.

Curators understand audiences but in a different way than $\mathrm{HCl}$ researchers understand users. New media art has and does create tensions between the artist as author and the actions of an audience. Manovich (1999) reflected on new media art, putting in the context of previous media and seeing how it had developed from earlier forms such as cinema. He also reflected on the changing nature of the audience, and hence, the changing nature of the relationship between artist and audience. From an $\mathrm{HCl}$ viewpoint it is natural to champion interactive art, and indeed, want to study the audiences experiences with such art. As Manovich reflects however, there are a variety of responses that an artist may which to tease our of an audience. They may wish them to be viewers, touchers and listeners, in the conventional sense. Or, they might want to create a platform for the audience-as-artist. These varieties of experience need also to be respected by the Interaction participant. We naturally wish to explore interactive technology and scenarios but they may be inappropriate to the artists' goals. Artists can take different roles in a project but one to guard against is that of a Disney-style Imagineer, coming up with new ideas on demand.

The Web has supported the growth of informal, collaborative art as documented by Blais and Ippolito (2006). However, these developments have not been studied much by $\mathrm{HCl}$ researchers. Indeed it could be argued that we do not have the right methods and tools to investigate them - or that we have allowed inappropriate usability methods to dominate, which restrict the styles of study we can carry out and the findings we can uncover. Similarly, many new media artists use visual programming tools, like MAXMSP that have great expressive power but are largely unknown, and have not been studied by $\mathrm{HCl}$ researchers. Thus there is a need to find new methods or adapt existing methods, e.g. action research, for $\mathrm{HCl}$ researchers to make studies of new media art production and practice.

$\mathrm{HCl}$ education as a subject has spread from Computer Science to Psychology, Sociology, and Management Information Systems and beyond. However, it does not seem to have had a similar impact on Art and Design. There is a feeling that $\mathrm{HCl}$ is science whereas Art and Design are crafted, in the wider sense of the term. What would an $\mathrm{HCl}$ for Arts and Design look like? It could follow the model of Manovich by putting interaction in the historical and theoretical context of art, rather than the operational, production-oriented view traditional in $\mathrm{HCl}$ education. Research studies as suggested about could become part of the documentation of the history of new media development. This would form the backbone of an $\mathrm{HCl}$ Arts and Design Curriculum. Cockton (2010) argues further that we need an Arts and Humanities approach to $\mathrm{HCl}$, bringing theories from aesthetics and philosophy. 


\section{CONCLUSIONS}

We have presented three art and interaction collaborative projects, which have reflected developments in practice in their contributing disciplines. Thinking in both new media art and $\mathrm{HCl}$ has evolved over the years to face new challenges, to provide new ways of investigation and exploration, and to provide new experiences for audiences/user. $\mathrm{HCl}$ still needs to develop to provide meaningful answers as to what makes an engaging and meaningful art experience. We need to study how artists work and how their project progress the art history of tomorrow. Collaborative arrangements need to be studied and the wide range of possible collaborations recognised. Additionally partners within a collaboration need to agree mutually beneficial goals for such multidisciplinary projects to succeed. Curators-asmediators provide a vital role in production projects. We also need to recognise the different viewpoints of artists and interaction design towards audiences and users. The Web and other highly leveraged tools provide greater scope for new media art development but need further study and better study methods from $\mathrm{HCl}$. Finally we need to consider the role of education: how do we develop an $\mathrm{HCl}$ curriculum for the Arts?

\section{ACKNOWLEDGEMENTS}

The above projects are the results of many peoples contributions: Wet and Sticky, Tunde Cockshott, Kevin Waite and John Patterson; Unmasking3, Ola Bamgboye, Marie-Anne McQuay, Maria Brewster, Daniel Tai, Liverpool World Museum; HCl Fun, Josh Nimoy, Caen Botto, Simon Poulter, Marta Ruperez, FACT, Matt Philp. 


\section{REFERENCES}

Bamgboye, O, England, D, Yu Ming Tai, (2001) "Unmasking 3 - A Framework for the Interactive African Art Museum", proceeding of Circus '01 Conference 2001, Glasgow, September.

Blais J, and Ippolito J, (2006) At the Edge of Art, Hudson Books

Candy, L, Edmonds E (2002), Explorations in Art and Technology: Intersections and Correspondence, Springer.

Carey R, Bell G, (1997), The Annotated VRML 2.0 Reference, Addison-Wesley

Cockton G, Bardzell, S, Blythe M, Bardzell J, (2010), Can we all stand under our umbrella: the arts and design research in $\mathrm{HCl}, \mathrm{CHI} 2010$ SIG meeting, ACM, New York.

Cockshott T (1991) "Wet and Sticky: A Novel Model for Computer-Based Painting", PhD Thesis, Glasgow University.
England D, Cockshott T, (1991) "Painting with wet paint on a Transputer-Based system", in Proceedings of Transputer Applications 3 (Durani et al, eds.), IOS Press, August

England D, Ruperez M, Botto C, Nimoy J, Poulter S, (2007) "Creative Technology and $\mathrm{HCl}$ ", Proceedings of the $\mathrm{HCl}$ Educators 2007, Annual international conference of Human-Computer Interactions Educators, March 29-30, Aveiro, Portugal.

Greenberg S, Buxton B, (2008), Usability Evaluation Considered Harmful (some of the time), Proceedings of $\mathrm{CHI} 2008$, ACM, New York.

Krueger. M (1991) Artificial Reality 2, AddisonWesley Professional, 1991.

Manovich L, (1999), The Language of New Media, MIT Press

Stockhausen, K. (1967). Mikrophonie I/Mikrophonie II. CBS 32110044 / S77 230 / 72647 (LP). 